\title{
Tensed Ontology based on Simple Partial Logic*
}

\author{
Daisuke Kachi
}

\begin{abstract}
Simple partial logic $(=\mathrm{SPL})$ is, broadly speaking, an extensional logic which allows for the truth-value gap. First I give a system of propositional SPL by partializing classical logic, as well as extending it with several non-classical truth-functional operators. Second I show a way based on SPL to construct a system of tensed ontology, by representing tensed statements as two kinds of necessary statements in a linear model that consists of the present and future worlds. Finally I compare that way with other two ways based on Łukasiewicz's threevalued logic and branching temporal logic.
\end{abstract}

\section{Simple Partial Logic}

SPL is a system of truth-functional logic that generalizes (propositional) classical logic $(=\mathrm{CL})$ by allowing for the truth-value gap. At the same time the SPL given in this paper is an extension of CL by adding several non-classical truth-functional operators which are reducible to one. Here I restrict my arguments to its syntax and semantics, omitting its proof theory.

There are two kinds of logical operators in SPL: the basic operators, which are also included in the syntax of CL, and the modal operators, which are not included. I show the operators and their semantics in the following tables:

Table 1: Basic operators

\begin{tabular}{|l||l|l||l|l|l|l||l|l|l||l||l|l|l|l||l|l|l|}
\hline $\mathrm{A}$ & $\sim \mathrm{A}$ \\
\hline $\mathrm{f}$ & $\mathrm{A} \& \mathrm{~B}$ & $\mathrm{t}$ & - & $\mathrm{f}$ & $\mathrm{A} \vee \mathrm{B}$ & $\mathrm{t}$ & - & $\mathrm{f}$ & $\mathrm{A} \rightarrow \mathrm{B}$ & $\mathrm{t}$ & - & $\mathrm{f}$ & $\mathrm{A} \leftrightarrow \mathrm{B}$ & $\mathrm{t}$ & - & $\mathrm{f}$ \\
\hline $\mathrm{t}$ & $\mathrm{f}$ \\
\hline- & - & $\mathrm{t}$ & $\mathrm{t}$ & - & $\mathrm{f}$ & $\mathrm{t}$ & $\mathrm{t}$ & $\mathrm{t}$ & $\mathrm{t}$ & $\mathrm{t}$ & $\mathrm{t}$ & - & $\mathrm{f}$ & $\mathrm{t}$ & $\mathrm{t}$ & - & $\mathrm{f}$ \\
\hline $\mathrm{f}$ & $\mathrm{t}$ & - & - & - & $\mathrm{f}$ & - & $\mathrm{t}$ & - & - & - & $\mathrm{t}$ & - & - & - & - & - & - \\
\hline & $\mathrm{f}$ & $\mathrm{f}$ & $\mathrm{f}$ & $\mathrm{f}$ & $\mathrm{f}$ & $\mathrm{t}$ & - & $\mathrm{f}$ & $\mathrm{f}$ & $\mathrm{t}$ & $\mathrm{t}$ & $\mathrm{t}$ & $\mathrm{f}$ & $\mathrm{f}$ & - & $\mathrm{t}$ \\
\hline
\end{tabular}

*Reprinted from Proceedings of Ninth International Symposium on Temporal Representaion and Reasoning: TIME-02, pp. 141-145, 2002. 
Table 2: Modal operators

\begin{tabular}{|l||l|l|l|l|}
\hline A & TA & FA & LA & MA \\
\hline \hline$t$ & $t$ & $f$ & $t$ & $f$ \\
\hline- & $f$ & $f$ & $f$ & $t$ \\
\hline$f$ & $f$ & $t$ & $t$ & $f$ \\
\hline
\end{tabular}

\begin{tabular}{|l||c|c|c|}
\hline $\mathrm{A} \longmapsto \mathrm{B}$ & $\mathrm{t}$ & - & $\mathrm{f}$ \\
\hline $\mathrm{t}$ & $\mathrm{t}$ & $\mathrm{f}$ & $\mathrm{f}$ \\
\hline- & $\mathrm{t}$ & $\mathrm{t}$ & $\mathrm{t}$ \\
\hline $\mathrm{f}$ & $\mathrm{t}$ & $\mathrm{f}$ & $\mathrm{f}$ \\
\hline
\end{tabular}

They are reducible, for example, to ' $\&$ ', ' $\sim$ ', ' $\mathrm{T}$ ' in the following way:

$\mathrm{A} \vee \mathrm{B}={ }_{d f} \sim(\sim \mathrm{A} \& \sim \mathrm{B})$

$\mathrm{A} \rightarrow \mathrm{B}={ }_{d f} \sim(\mathrm{A} \& \sim \mathrm{B})$

$\mathrm{A} \leftrightarrow \mathrm{B}=d f(\mathrm{~A} \rightarrow \mathrm{B}) \&(\mathrm{~B} \rightarrow \mathrm{A})$

$\mathrm{FA}={ }_{d f} \mathrm{~T} \sim \mathrm{A}$

$\mathrm{LA}={ }_{d f}$ TA $\vee \mathrm{FA}$ ('A' has a truth-value.)

$\mathrm{MA}={ }_{d f} \sim \mathrm{LA}$

$\mathrm{A} \mapsto \mathrm{B}=_{d f} \mathrm{LA} \rightarrow \mathrm{TB}($ 'A' presupposes 'B'.)

I call the intermediate value 'gap-value', distinguishing it from 'truthvalues', which refer only to truth and falsity. The formula that does not include modal operators are called 'basic formula'.

The definitions of the basic operators coincide with those of Kleene's strong three-valued logic and have the following semantic properties: ${ }^{1}$

\section{(1)Reliable Determinability (=Reliability)}

The truth-tables that define the meaning of the base-operators in SPL coincide with those of CL under total valuation. ${ }^{2}$ In other words, a basic formula has the same truth-value with that of CL, if all the atomic formulae included have truth-values.

\section{(2)Monotonicity}

If the basic formula that includes gap-valued (=gapped) atomic formulae has a truth-value, it does not make its truth-value change by altering the gap-value to a truth-value.

\section{[Definition]}

One operator is stronger than another under partial valuation. ${ }_{d f}$ The former gives a truth-value to the formula which it bounds, whenever the latter gives one to the same formula.

\section{(3)Strength}

\footnotetext{
${ }^{1}$ In this paper I adopted most of Langholm's terminology for partial logic, except for 'monotonicity', which he calls 'persistence'. [Langhholm,T. 1988][Langhholm, T. 1996]

${ }^{2}$ I call the truth-valuation where every atomic formula is assigned a truth-value 'total valuation'. The valuation which is not total is 'partial valuation'.
} 
The above basic operators are the strongest ones that are reliable and monotonic among those based on CL.

Modal operators have the following properties: ${ }^{3}$

\section{(1) Strong Determinability}

Modal operators always bring about a truth-value under partial valuation.

\section{(2)Weak Monotonicty}

If a basic formula has a truth-value, it does not make its truth-value lost (namely, be changed to the gap-value) by altering the gap-value to a truth-value (this is a corollary of strong determinability).

We can understand the strong determinability as resulting from a kind of self-referring function of the modal operators, which describe the partiality of truth-valuation itself. Accordingly it destroys the monotonicty of SPL but it keeps the weakened monotonicity given above.

Now I define two conceptions of validity in SPL: ${ }^{4}$

(1)Weak Validity (=being w-valid)

$\Sigma \models{ }_{w} \mathrm{C}$ iff there are no partial valuations which make all the formulae in the set $\Sigma \cup\{\sim \mathrm{C}\}$ true.

(2) Strong Validity (=being s-valid)

$\Sigma \models{ }_{s} \mathrm{C}$ iff there are no partial valuations which make all the formulae in the set $\Sigma \cup\{\sim \mathrm{C}\}$ non-false (=true or gapped).

Adopting these definitions of validity, the following semantic theorems hold:

[Th1]

$\Sigma \models_{w} \mathrm{C}$ if $\Sigma \models_{s} \mathrm{C}$

[Th2w] Weak Deduction Theorem (WDT)

$\mathrm{P}_{1}, \mathrm{P}_{2},-, \mathrm{P}_{n} \models{ }_{w} \mathrm{C}$ iff $\models_{w}\left(\mathrm{P}_{1} \& \mathrm{P}_{2} \&-\& \mathrm{P}_{n}\right) \rightarrow \mathrm{C}$

[Th2s] Strong Deduction Theorem (SDT)

$\mathrm{P}_{1}, \mathrm{P}_{2},-, \mathrm{P}_{n} \models_{s} \mathrm{C}$ iff $\models_{s}\left(\mathrm{P}_{1} \& \mathrm{P}_{2} \&-\& \mathrm{P}_{n}\right) \rightarrow \mathrm{C}$

[Th3w] Weak Contraposition Theorem (WCT)

$\mathrm{P}_{1}, \mathrm{P}_{2},-, \mathrm{P}_{n} \models_{w} \mathrm{C}$ iff $\models_{w} \sim \mathrm{C} \rightarrow \sim\left(\mathrm{P}_{1} \& \mathrm{P}_{2} \&-\& \mathrm{P}_{n}\right)$

[Th3s] Strong Contraposition Theorem (SCT)

$\mathrm{P}_{1}, \mathrm{P}_{2},-, \mathrm{P}_{n} \models_{s} \mathrm{C}$ iff $\models_{s} \sim \mathrm{C} \rightarrow \sim\left(\mathrm{P}_{1} \& \mathrm{P}_{2} \&-\& \mathrm{P}_{n}\right)$

\footnotetext{
${ }^{3}$ Most of the modal operators coincide with the operators which Woodruff adopted for his three-valued logic 'System Q'. [Woodruff, P. 1970]

${ }^{4}$ I have given the justification of these definitions and the proofs of the following semantic theorems in my paper: [Kachi, D. 2002]
} 


\section{[Definition]}

$\Sigma \models_{c} \mathrm{C}={ }_{d f}$ The argument which derives $\mathrm{C}$ from $\Sigma$ is valid in CL.

(This implies that the argument includes only the basic formulae.)

[Th4]

$\Sigma \models_{w} \mathrm{C}$ iff $\Sigma \models_{c} \mathrm{C}$

[Th5]

There are no s-valid arguments that include only the basic formulae.

The holding of both the deduction theorem and the contraposition theorem is one of the reasons why I adopt these definitions of validity. Other possible definitions lack this property. ${ }^{5}$ [Th4] establishes that SPL is an alternative way to the supervaluational logic to keep classical validity allowing for the truth-value gap. It is preferable at least in keeping truthfunctionality. In contrast [Th5] shows that strong validity is proper to SPL. The following are among the s-valid arguments:

$$
\begin{aligned}
& \mathrm{TA} \models_{s} \mathrm{~A}\left(\mathrm{cf} . \mathrm{A} \not \models_{s} \mathrm{~A}, \mathrm{~A} \not \models_{s} \mathrm{TA}\right) \\
& \mathrm{LA} \models_{s} \mathrm{~A} \vee \sim \mathrm{A}\left(\mathrm{cf} . \nvdash_{s} \mathrm{~A} \vee \sim \mathrm{A}\right) \\
& \models_{s} \mathrm{TA} \vee \sim \mathrm{TA}\left(\mathrm{cf} . \nvdash_{s} \mathrm{TA} \vee \mathrm{T} \sim \mathrm{A}\right) \\
& (\mathrm{A} \mapsto \mathrm{B}) \& \mathrm{LA} \models_{s} \mathrm{~TB}
\end{aligned}
$$

\section{Application of SPL to the Ontology of Time}

One of the fields of the application of SPL is the theory of presupposition (indeed one of the meta-operators ' $\mathrm{A} \mapsto \mathrm{B}$ ' is to be read as 'A presupposes B'). We can interpret ' $\mathrm{TA}$ ' as a statement with the presupposition of having a truth-value; it insists that (it is presupposed that) ' $A$ ' has a truth-value and it is the case that A. In fact the following theorem holds:

$$
\models_{s} \mathrm{TA} \leftrightarrow(\mathrm{LA} \& \mathrm{~A})
$$

In contrast, we should take 'A' as a statement which lacks such a presupposition, and so it is valued as 'truth-valueless' or 'gapped' when the presupposition fails. Or we can also understand ' $\mathrm{A}$ ' as a conditional statement, 'If ' $\mathrm{A}$ ' has a truth-value it is the case that A.' However, it should be noted here that we must not take this conditional as a two-valued material conditional. If we did, 'A' would become true whenever it lacks a truthvalue, which appears contradictory. Rather it means that the statement ' $A$ ' has effects only if it has a truth-value and that it will be cancelled when it does not.

\footnotetext{
${ }^{5}$ As for the examples of other definitions, see the following: [Blamey, S. 1986] [Busch, D. 1996] [Fenstad, J. E. 1997]
} 
Let's call ' $\mathrm{TA}$ ' and 'A' respectively 'a strong statement' and 'a weak statement'. For example, we can interpret a historical statement 'Caesar crossed the Rubicon' as a strong statement, while a fictional statement 'Alice went into Wonderland' as a weak statement. Usually we use the former statement presupposing that it actually has a truth-value, while it depends upon the context or the convention whether the latter has a truth-value and so we take it to be sometimes truth-valueless.

Moreover we can use the above two kinds of statements to distinguish strong necessity and weak necessity in the theory of modality. A strong necessary statement '[]TA' insists on the holding of a fact in every possible world unrestrictedly. On the other hand a weak necessarily statement '[]A' does it restrictedly to the possible worlds where the statement has a truth-value. Usually the distinction depends on whether the referents in the statement exist in every possible world. For example, 'It is necessary that $2+2=4$ ' and 'It is necessary that God is almighty' usually insist on strong necessity, while ' $\mathrm{It}$ is necessary that water is $\mathrm{H}_{2} \mathrm{O}$ ' and 'It is necessary that Socrates is mortal' assert weak necessity.

Finally there is a way to apply SPL to the ontology of time, which we can take as a special case of the above modal application. Firstly let's assume that the possible worlds concerned here are the present and future worlds. However, the worlds considered here are not the presentistic ones as in the semantics of tense logic, but rather four-dimensionalistic ones. Put concretely, this means that the atomic formulae supposed here are not the present-tensed ones such as 'It is cloudy in Saitama now', but tenseless ones with dates, such as 'It [is] cloudy in Saitama at noon on the 14th February 2002('[is]' signifies that it is tenseless).' At the same time tenseless statements with earlier or later dates are also included among the atomic formulae which describe the same world.

Next let's adopt the model $\langle W, R, V\rangle$ which I call 'the future model', where $W$ is a set whose elements are the present and future worlds, and $R$ is a binary relation between the worlds, and $V$ is a partial valuation in the worlds. The future model is prescribed according to the following rules:

(1)All the worlds are lineally ordered according to their dates that are uniquely indexed to each world.

(2)There is a world that has the earliest date among the worlds, namely the present world.

(3)If an atomic formula has a truth-value in a world, it has the same truth-value in all the worlds that are later than the world.

(4)Every atomic formula has a truth-value at least in one world. 
Assuming this model, let's introduce the distinction between strong necessity and weak necessity. If we adopt the operator ' $G$ ' as meaning 'in every present and future world', we can define the truth-condition of 'GTA' and 'GA' in the following way:

\section{[Definition]}

'GTA' is true in the future model. $={ }_{d f}$ ' $\mathrm{A}$ ' is true in every world in the future model.

' $\mathrm{GA}$ ' is true in the future model. $=_{d f}$ ' $\mathrm{A}$ ' is true in every world where ' $\mathrm{A}$ ' has a truth-value in the future model.

The monotonicity of the atomic formulae given by (3) and the monotonicity of the basic operators, together with (4), make the following theorems hold for the future model:

\section{[M1]}

If 'A' is a basic formula, a strong necessary statement 'GTA' is true in the future model iff ' $\mathrm{A}$ ' is true in the present world.

[M2]

If ' $\mathrm{A}$ ' is a basic formula, a weak necessary statement ' $\mathrm{GA}$ ' is true in the future model iff there is a world in which ' $\mathrm{A}$ ' is true and in all the worlds earlier than which ' $\mathrm{A}$ ' is gapped (if there are).

By [M2], if ' $\mathrm{A}$ ' is a basic formula, we can take a weak necessary statement 'GA' in this model as a future-tensed statement within the framework of dynamic ontology according to which it lacks a truth-value until the moment when the stated event is determined to occur or not. In contrast, a strong necessary statement 'GTA' whose 'A' is a basic formula corresponds to a past- or present-tensed statement. If we can characterize our ordinary tensed statements in such a way, it turns out that all of our ordinary tensed statements are (weak or strong) necessary statements in the sense defined for the future model.

So if we confine ourselves within our ordinary tensed statements, namely 'GTA' and 'GA' whose 'A's are only basic formulae, we can dispense with the intensional operator ' $G$ ', since we can take it as always accompanying the tensed statements implicitly. Moreover, by the combination of [M1] and [M2], we can reduce the difference between the statements 'GTA' and 'GA' to the difference as to whether they insist that the present world is the earliest world in which ' $A$ ' is true or it is not necessarily so, although both insist that ' $A$ ' is eternally true from some world on. That is to say, we can reduce the difference between the statements about many worlds into the 
difference between their description about one world, namely the present world.

\section{Comparison with Łukasiewicz's Three-valued Logic and Branching Temporal Logic}

As is well known, Łukasiewicz's three-valued logic, which I call the system $\mathrm{E}_{3}$, was intended to deal with the future contingency. He tried to construct a truth-functional modal logic which does not result in determinism when its necessity is construed as the determination of events. However, he abandoned it in his later years for the reason that it does not make contradiction ('A\& A') necessarily false, while it makes identity ('A $\rightarrow$ A') necessarily true, though he positively accepted the failure of excluded middle ('A $\vee \sim A$ ') as the denial of determinism.

The truth-table for the operator ' $\mathrm{T}$ ' in SPL is the same as that for the necessity operator ' $\mathrm{L}$ ' in the system $\mathrm{E}_{3}$. In fact under the interpretation given above, they play the same role, though I would rather interpret the lack of truth-value of a statement not as the result of causal indetermination of the stated events, but as the result of the lack of its truth-maker.

The truth-tables of the basic operators of SPL only differ from those of the system $\mathrm{E}_{3}$ in terms of the value of the conditional (and biconditional) when both of its subformulae are gapped. The former makes it gapped, while the latter makes it true. Accordingly SPL does not make identity necessarily true either. In fact it is the corollary of [Th5] in the first section that no classical tautology is a strong tautology, which means that it is always true under partial valuation. Łukasiewicz's conditional is non-monotonic and we can define it as '(MA\&MB $) \vee(A \rightarrow B)$ ' using Kleene's monotonic conditional. And so we should rather understand it as a derivative operator.

On the other hand, the laws of excluded middle, identity and contradiction are all preserved in SPL as weak tautologies, which is the corollary of [Th4]. We can understand a weak tautology as a formula which is always true whenever it has a truth-value (as I have stated above, we must not take this conditional as a two-valued material conditional). In other words, SPL takes the failure of the classical tautologies not as the destruction of the laws of CL but only as the result of the lack of a truth-maker, which is not a logical but an ontological matter. In that sense SPL is not an alternative of CL but just its generalization by allowing for the truth-value gap.

Another way of dealing with the future contingency is to adopt a branching model in which the future worlds are partially ordered by dates. There 
are two views on the way to represent a future-tensed statement in the branching model. One is 'Peirce's view', which takes a future statement as a kind of necessary statement which insists on the occurrence of a future event in every branch. The other is 'Ockham's view', which takes a futuretensed statement as a contingent statement which insists on the occurrence of a future event in one of the branches that is called a 'prima facie future branch'.

However, both have defects. Firstly they do not reflect correctly our ordinary usage of the future-tensed statements. Peirce's future-tensed statement seems too strong, because usually we do not insist on the present determination of the occurrence of a future event, when we make a future-tensed statement. If we did, it would be nothing but a present-tensed statement. On the other hand, Ockham's future-tensed statement appears too weak, because there is no formal distinction between the prima facie branch and the other branches, and so the statement is not different from the statement which only insists on the possibility of the occurrence of the future event.

Secondly, I think that the branching model is ontologically improper as a model that represents the dynamic change of the world itself-the so called 'temporal flux'. In my view the future contingency should be interpreted not as the result of the present causal indeterminacy of future events but as the result of the present lack of its truth-maker. Therefore SPL, which deals with the truth-value gap, seems more relevant with the dynamic ontology which takes account of the passage of time.

And finally, from a formal point of view, a linear model of the future worlds is simpler than a branching model. So it is at least worth investigating how far we can represent the complexity of our tensed statements within the framework of a linear model. Indeed we saw at the end of the last section that we can dispense with intensional operators and can truth-functionally represent our ordinary tensed statements in a linear model of the future worlds. In that sense I believe that Lukasiewicz was right in his motive for constructing his system $\mathrm{L}_{3}$ to deal with the problem of future contingency extensionally.

As for the first problem of the branching model, I believe that my interpretation of the future-tensed statements as a weak necessary statement is free from both the defects of Peirce's view and Ockham's view. My view goes midway between Peirce's and Ockham's. On the one hand it is closer to the former, because it takes a future-tensed statement as a kind of necessary statement. But it is different in that it takes a future-tensed statement not as the description of the determination in the present world but as the description of all the present and future worlds. On the other hand, my 
interpretation is similar to Ockham's view, in that my view also seems to imply that insisting on the occurrence of a future event is compatible with admitting its contingency. However, my view does not appear to threaten a future-tensed statement to degenerate into just a possibility statement.

\section{REFERENCES}

1. Blamey, S. (1986), Partial Logic, in [Gabbay, D. and Guenthner, F. (Eds.) 1986] pp.1-70.

2. Busch, D. (1996), Sequent Formalization of Three-Valued Logic, in [Doherty, P. (Ed.) 1996] pp.45-75.

3. Fenstad, J. E. (1997), Partiality, in [Van Benthem, J. and Ter Mulen, A. (Ed.) 1997] pp.649-682.

4. Gabbay, D. and Guenthner, F. (Eds.) (1986), Handbook of Philosophical Logic 3, D.Reidel.

5. Kachi, D. (2002), Validity in Simple Partial Logic, to appear in Annals of the Japan Association for Philosophy of Science 10-5.

6. Langhholm, T. (1988), Partiality, Truth and Persistence, CSLI.

7. Langhholm, T. (1996), How Different is Partial Logic?, in [Doherty, P. (Ed.) 1996] pp.3-43.

8. Lambert, K. (Ed.) (1970), Philosophical Problems in Logic, D.Reidel.

9. Van Benthem, J. and Ter Mulen, A. (Eds.) (1997), Handbook of Logic and Language, Elsevier Science B. V.

10. Woodruff, P. (1970), Logic and Truth-Value Gaps, in [Lambert, K. (Ed.) 1970] pp.121-142. 